\title{
Comparative analysis between global sukuk and bond indices: value-at-risk approach
}

\author{
Rubaiyat Ahsan Bhuiyan and Maya Puspa
}

Faculty of Economics and Management Sciences, International Islamic University Malaysia, Kuala Lumpur, Malaysia

Buerhan Saiti

Department of Islamic Economics and Finance, Istanbul Sabahattin Zaim University, Istanbul, Turkey, and

Global sukuk and bond indices

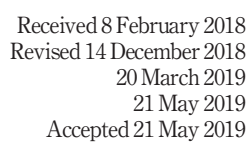

Received 8 February 2018

Revised 14 December 2018

20 March 2019

21 May 2019

Accepted 21 May 2019

\section{Gairuzazmi Mat Ghani} \\ Faculty of Economics and Management Sciences, \\ International Islamic University Malaysia, Kuala Lumpur, Malaysia
}

\begin{abstract}
Purpose - Sukuk is an innovative financial instrument with a flexible structure based on Islamic financial contracts, unlike a bond which is based on the structure of a loan imposed with interest. With the notion that sukuk differs considerably from the conventional bonds in terms of risks related to investment, this study aims to examine whether the sukuk market is different from conventional bond markets based on the valueat-risk (VaR) approach.

Design/methodology/approach - The VaR of a portfolio consists of sukuk and bond indices and is undertaken to determine whether there is any reduction in the $\mathrm{VaR}$ amount through the inclusion of the sukuk index in the portfolio. The analysis is undertaken based on the developed and emerging market bond and sukuk indices from January 2010 to December 2015.

Findings - This paper examines whether the VaR of sukuk market differs from conventional bond markets by using fundamental techniques. It was observed that the VaR amount of sukuk indices is comparatively much lower than the VaR of bond indices in all the cases. Including the sukuk index with each bond index can reduce the VaR of the portfolio by around 30 to 50 per cent for all the developed and emerging market bond indices.

Research limitations/implications - This research is limited to covering six years of data. Nonetheless, it is able to provide findings which are believed to be useful for the market players.

Practical implications - This study unveils attractive opportunities in terms of diversification benefits of sukuk indices for international fixed-income portfolios.

Originality/value - The VaR method is a useful risk management tool. This study uses this method to emphasise the significant reduction of risks and diversification benefits that sukuk investment could offer by including it in the investment portfolio.
\end{abstract}

Keywords Sukuk, Bond, Value-at-risk, Portfolio management, Islamic finance

Paper type Research paper

The authors are deeply grateful to Co-Editor Dr Mohammad Hudaiband and the anonymous reviewers for their helpful comments which improved the quality of the paper greatly. The authors acknowledge and assume responsibility for any mistakes or errors within the manuscript.

Journal of Islamic Accounting and Business Research Vol. 11 No. 6, 2020 pp. $1245-1256$ c Emerald Publishing Limited $1759-0817$ DOI 10.1108/JIABR-02-2018-0019 
JIABR 11,6

\section{Introduction}

The sukuk market has recorded substantial and remarkable growth over the past decade. In recent years, sukuk has gained more importance globally because of its significant performance as a flagship Islamic capital instrument. The global sukuk outstanding topped US $\$ 30 \mathrm{bn}$ as of November 2014 and experienced an 11.4 per cent increase from US\$269.4bn at the end of 2013. An increasing trend was observed in Malaysia's secondary sukuk market, which was sizeable at approximately US\$173.4bn at the end of 2014 with a 9.6 per cent increase year-on-year. At the same time, the total GCC sukuk outstanding portfolio rose by 6.4 per cent to US\$90.8bn, compared with US $\$ 85.3 \mathrm{bn}$ outstanding at the end of 2013 (Malaysia International Islamic Financial Centre, 2014). In terms of share of the total issuance among leading countries, Malaysia occupied 64.6 per cent, with Saudi Arabia (10.3 per cent), Indonesia (5.3 per cent), the UAE ( 5 per cent) and Turkey (3.6 per cent) rounding up the top five markets, where it was observed that Malaysia continued to dominate the market. However, the top five countries occupied approximately 95 per cent of the total issuance in 2013, whereas it was reduced to 89 per cent in 2014, which indicates that the sukuk market is distributed geographically. This is also a positive sign of expansion into a new market.

A diverse investor base participated in the sukuk market, reflecting 29 per cent investment from the USA, 39 per cent investment from the Middle East and Asia and 31 per cent from Europe. The UK played a key role in Shariah-compliant finance in the eurozone and issued its debut sukuk in 2014. As a whole, 19 countries tapped the sukuk market this year, compared with 18 countries in 2013 reflecting mainly debut sukuk (Kuwait Finance House Research Ltd., 2015) by the governments of the UK, South Africa, Pakistan, Hong Kong, Senegal, Luxembourg and the Emirate of Sharjah. Also, the Central Bank of Bangladesh issued a short-term sukuk to manage liquidity, which was a positive step for its introduction into Islamic finance[1].

According to the Accounting and Auditing Organization for Islamic Financial Institutions, sukuk can be described as "certificates of equal value representing undivided shares in ownership of tangible assets, usufruct, and services, assets of particular projects or special investment activity". Conventional bonds differ significantly from sukuk in such a way that the return to bondholders or investors signify the right to claim indebtedness for borrowed money, whereas the return to sukuk holders signifies the right to avail payments from a trade transaction and claim ownership of business venture or a specific asset (Kuwait Finance House Research Ltd., 2015). Moreover, sukuk is an innovative financial instrument having a flexible structure based on Islamic financial contracts, unlike a bond which is based on the ancient structure of a loan imposed with interest. Sukuk is not an interestbased financial instrument but one that promotes real economic activities and generates a return based on sharing or leasing acceptable assets (RAM Rating Services Berhad, 2008).

Furthermore, sukuk differs considerably from conventional bonds in terms of risks related to investment. Sukuk is influenced by the Shariah compliance risk, which is associated with the structure that originates from the usage of Islamic finance contracts. Apart from this, sukuk faces similar risks associated with bonds such as credit risk, business risk, foreign exchange risk, liquidity risk, commodity risk and market risk which are considered an interest rate risk and equity price risk (Tariq, 2004).

Turbulence in the global financial market in 2007/2008 had set off a sporadic pattern which affected the yields of the treasury bills, government and corporate bonds globally as an after-effect of the quick changes in monetary policy. For instance, the yield on the US 10year treasury bill descended from its top of 4.27 per cent in June 2008 to its record drop to a low of 2.05 per cent in December 2008[2] when the interest rate was reduced as the primary 
remedial measure to assist economic activity using financing and customer spending mechanisms[3]. The same example was also seen in the European Union and the UK where long-haul sovereign security yields lost by more than 150 basis points, whereas Japan's yields plunged by 60 basis points from their peak in 2008 (Wilson, 2010). Moreover, the global effects brought about by the financial crisis provoked numerous researchers to examine the Islamic financial system. Smolo and Mirakhor (2010) observed that the Islamic financial industries were protected from the crisis because of the fundamental Shariah restriction prohibiting riba (Interest) and gharar (pointless fallacy). Smolo and Mirakhor

Global sukuk and bond indices (2010) affirmed that the impermissibility and consequently, inaccessibility of financial derivatives, such as the Collateralized Debt Obligations, may have been a vital contributor to protecting the Islamic financial system from suffering the vast effects of the crisis.

Therefore, we are wondering whether sukuk has similar a risk-return profile to that of bonds. The present study examines whether the value-at-risk (VaR) of sukuk market differs from conventional bond markets by using fundamental techniques. It also examines the $\mathrm{VaR}$ of a portfolio consisting of sukuk and bond indices to determine whether there is any reduction in VaR amount through the inclusion of sukuk index in the portfolio.

Section 2 highlights the literature on VaR and diversification benefits of sukuk and bond markets. Section 3 provides detailed descriptions of the methodology used to investigate the $\mathrm{VaR}$ of sukuk and the bond market portfolio. Section 4 contains a description of the data, the application of the methodology and a detailed discussion of the findings. Section 5 concludes the study. The implication of this research is also highlighted together with its limitations and recommendations for future research.

\section{Literature review}

Sukuk gained more importance globally because of its significant performance as a flagship Islamic capital instrument. Afshar (2013) uncovered the issue of compatibility of sukuk instruments with conventional considering the structure and risk-return profile. The author also addressed the issue from the investors' and issuers' perspectives, where both can choose sukuk and conventional bonds because both financial instruments are successful in generating capital for corporations and governments. However, these two instruments differ in nature, given that sukuk instruments are based on equity, whereas conventional bonds are debt-based instruments.

Most of the studies focused on a comparative analysis between sukuk and the conventional bond market in terms of structure. A few empirical studies analysed the risk and return profiles between the two. For instance, Zin et al. (2011) compared sukuk and conventional bonds in the context of the Malaysian market and highlighted the practices and prospects of sukuk in the Malaysian Islamic capital market. Furthermore, Ariff and Safari (2012) investigated the existence of causality factors between the performance of sukuk and conventional bonds which have similar yields and ratings but discovered that there was no causality between the two. Lahsasna and Lin (2012) investigated Shariah issues in sukuk structure and claimed that there were similarities between sukuk and conventional bonds in terms of the late-payment penalty, trading of debt-based sukuk, purchase undertaking in equity-based structure and ownership status in the asset-based transaction. Fathurahman and Fitriati (2013) examined the yields of sukuk and conventional bonds within the Indonesian bond market. The researchers found a significant difference between the yields on sukuk instruments and the conventional bonds. In addition, the yields on sukuk were greater than conventional bonds. Ramasamy et al. (2011) examined sukuk in terms of duration and convexity compared to government and corporate bonds and measured the sensitivity of sukuk 
JIABR 11,6 traded in Malaysia. The outcome of the study provided evidence that a sukuk holder gets a higher return compared to government bonds and at a lower rate than conventional bonds. Moreover, the author believed that a conventional bond is relatively riskier compared with sukuk. Alswaidan et al. (2017) worked on the creation of evidence-based risk management techniques in Islamic finance and the expansion of ethical financial management. Their findings revealed that sukuk structures are directly related to sukuk risk profiles. Thus, sukuk structure risks are Shariah risks. This study highlights a sukuk risk classification matrix based on an estimation of sukuk structure risks.

Rahman et al. (2013) studied sukuk spreads applying the generalized autoregressive conditional heteroskedasticity (GARCH) method. This study examined factors that influenced sukuk spreads and its volatility, which has contributed to the empirical literature related to Islamic financial markets. It uncovered the underlying factors which influenced risk management and pricing of sukuk instruments. Moreover, the authors assessed the impact of the recent financial crisis on the behaviour of sukuk spreads and pre-empted the effects of future financial shocks on the Islamic bond market. Godlewski et al. (2013) examined the behaviour of Malaysian investors to the declaration of conventional bonds and sukuk issuance. The study observed that the stock market responded negatively to the declaration of sukuk issuance. On the other hand, it was neutral to the announcements of conventional bond issuance. Also, the authors emphasised that there were excessive demands for sukuk securities, and the adverse selection mechanism showed that lower-company debtor firms are the issuers of sukuk certificates. A recent study also highlighted the influence of macroeconomic factors on sukuk market development. Ahmad et al. (2012) examined the effect of macroeconomic factors on sukuk issuance in the Malaysian capital market at the aggregate level. The outcome of the study showed that sukuk Granger-caused gross domestic product (GDP) whereas GDP Granger-caused consumer price index and producer price index, and in the short horizon, sukuk are influenced by their own dynamics. Because GDP is Grangercaused by sukuk issuance, this is a very important finding for decision makers for designing and developing the functional features of the capital market.

In the case of other aspects of sukuk research, Ben Jedidia Khoutem (2014) studied the opportunities of Islamic finance in spurring economic development in Tunisia after the revolution of 2011. Precisely, this paper explores whether the Islamic banks-sukuk markets relationships are conducive of economic growth. The study finds that the "marketable Islamic intermediation" provides more funds to finance economic development and solve the problems of poverty and unemployment. Sherif and Erkol (2017) examined the stock market effects of announcements by firms to issue conventional bonds versus sukuk. In addition, the authors investigated whether the choice of instrument depends on the tax status and government backing of the issuing firm. Razak et al. (2018) examined the contracts, structures and pricing mechanism of sukuk. More specifically, their study investigated several sukuk instruments, reviewed the existing structures, demonstrated sukuk pricing mechanisms and discussed critical issues of each type of sukuk.

Bhuiyan et al. (2019a) studied the market links (and price discovery) between global sukuk by using the wavelet approach, which has recently been imported to finance from engineering sciences. Hamzah et al. (2018) investigated the extent of risk-shifting behaviour in bonds and sukuk. The examination is significant, as economists and scholars identify risk-shifting as the primary cause of the global financial crisis. Bhuiyan et al. (2018, 2019b) examined the volatilities and correlations of bond indices of emerging and developed counties by applying wavelet coherence and multivariate GARCH analyses. 
A handful of studies engaged in portfolio's risk analysis of sukuk and bond applying the VaR approach. To this end, Raei and Cakir (2007) examined the impact of sukuk on the cost and risk structure of investment portfolio applying the VaR methodology. The authors found different behaviour while comparing sukuk with Eurobonds issued by the same issuer. However, the portfolio's risk can be minimised by incorporating sukuk along with bonds. Paltrinieri et al. (2015) examined the VaR of sukuk and bond indices using the deltanormal VaR approach and found results similar to those of Raei and Cakir (2007). The findings implied that the sukuk index confirmed a lower level of risk measures. Moreover, lower volatility contributed to lower risks together with the low correlation in the portfolios. In Hassan (2012), the diversification benefit of the fixed-income portfolio was examined to compare between conventional bond and sukuk by adding and omitting sukuk in the same portfolio. In a recent study, Nasir and Farooq (2017) showed the comparative risk analysis of sukuk and bonds in Pakistan. The VaR approach was used to calculate the risk of two portfolios constructed separately with equal investments. The findings revealed that bonds are riskier and less stable compared with sukuk. It was also found that most of the sukuk securities are negatively or less-correlated to the constructed portfolio. In this study, we examine the VaR of a portfolio which consisted of sukuk and bond indices and determined whether there is any reduction in the VaR amount through the inclusion of the sukuk index in the portfolio.

\section{Methodology}

\subsection{Value-at-risk method}

The VaR measures the worst expected loss of a portfolio over a certain holding period at a given confidence level under normal market conditions (Jorion, 2006). In other words, VaR is an expression of the portfolio's market risk, representing the maximum amount which may be lost, during a holding period, in all but (say) 1 per cent of cases. For example, the VaR method can state with either 1 per cent probability or a 99 per cent confidence level that a certain amount of dollars will be lost in each day, month or year. Various methods, including simulation techniques, are applied to estimate the distribution of future portfolio values and to calculate the possible losses by using historical data. VaR is based on the variance of the return on the portfolio:

$$
\sigma_{P}^{2}=w \sum w^{\prime}
$$

where:

$\mathrm{W}=$ vector of weights for the various securities in the portfolio;

$\mathrm{w}^{\prime}=$ transposed vector of weights in the portfolio;

$\Sigma=$ variance-covariance matrix of returns on securities in the portfolio; and

$\sigma_{P}^{2}=$ standard deviation of the portfolio.

The VaR of a portfolio can be constructed from a combination of the risks of underlying securities. In other words, it constitutes the envelope for the volatility of, and correlation among, various risk variables over time. Several methods can be used to calculate VaR.

The variance-covariance approach, also called the delta-normal approach, is a commonly used method. The basic assumption in this method is that returns are jointly normally distributed. The normal curve conveniently enables us to determine where the worst 5 and 1 per cent lie on the curve, depending on the confidence
Global sukuk and bond indices

1249 
JIABR 11,6

interval, mean and standard deviation. Hence, we can calculate the portfolio VaR by using the equation:

$$
\mathrm{VaRp}=-\left(\mu_{p}-\alpha \sigma_{p} \mathrm{~W}\right)
$$

where:

$\alpha=$ standard normal deviate (e.g. 2.33 for the 99 per cent confidence level);

$\mu_{p}=$ average return of the portfolio; and

$\mathrm{W}=$ initial portfolio value

As it is clear from the formula for the VaR of an asset, lower volatility implies a smaller VaR, which is desirable. In the case of a portfolio of assets, lower volatility is obtained if the returns of constituent assets have small or even negative correlations. Gains from diversification arise by diversifying the portfolio to assets whose returns are not highly positively correlated.

The normality assumption makes the VaR computation convenient although it has some drawbacks. Contrary to the symmetry embodied in the normal distribution, asset returns diverge from symmetry in two common ways. Fat tails are common in asset returns, meaning that extraordinary losses may happen more frequently than a normal distribution predicts. Moreover, asset returns are often negatively skewed, with more observations on the left-hand side than on the right-hand side (Jorion, 2006).

In contrast to the delta-normal method, historical simulation is the simplest approach among other methods to estimate VaR of a portfolio. This approach works based on historical changes in the market price to identify probable future losses and profits. This approach involves accumulating the set of risk factor changes over a historical period, such as daily fluctuations over the last 10 years. This approach assumes a set of scenarios, which is a good representation of all outcomes that could happen between today and tomorrow. The instruments in the portfolio are repetitively re-valued against each of the scenarios. This helps to produce a distribution of portfolio values or distribution of changes in portfolio value from today's value. Commonly, some of these fluctuations will involve losses and some changes will involve profits. This study estimated the VaR of a portfolio from the maximum loss associated with the required statistic likelihood percentile.

The main advantage of historical simulation is that it is considered a non-parametric method because it does not hold any assumption on a probability distribution, such as the distribution of returns or risk factors. Nonetheless, it assumes there will be a repetition of previous historical events in the near future. Another significant advantage is that it does not include the estimation of any statistical parameters like variance or covariance. Finally, this approach is easy to explain and defend to an important and non-technical audience, such as the board of directors.

The limitation of the method is that it places equal weight on recent as well as past data that may cause bias estimation if there are trends like high volatility, which exist in the historical data. Moreover, it requires bulk data to detect rare events, and the past may have a different sort of risk characteristic from the future. This study applied delta-normal and historical simulation VaR methods to evaluate portfolio risk (Alexander, 2009).

\section{Data and empirical results}

\subsection{Data}

Data was collected from the Bloomberg and Datastream databases which covered the period from January 2010 to December 2015. These bonds and sukuk indices were transformed to 
bond market returns by computing the natural logarithmic differences of the daily bond or sukuk prices, that is, return $=\ln \left(\frac{p_{t}}{p_{t-1}}\right)$, where $P_{t}$ and $P_{t-1}$ represents the bond or sukuk price index at time $t$ and $t$ - 1 , consecutively. The list of the indices and the respective symbols are mentioned in Table I. The selected Bloomberg sovereign bond indices are a rule-based market-value weighted index constructed to measure the fixed-rate local currency securities publicly by respected countries. The selected Dow Jones Sukuk Index is constructed to evaluate the performance of global Islamic fixed-income securities or sukuk. This index incorporates US dollar-denominated investment-grade sukuk issued in the global market. Finally, the Thomson Reuters BPA Malaysia Government Sukuk Index includes the Malaysia Ringgit dominated long-term investment graded Islamic bonds.

\subsection{Findings}

Before analysing the portfolios, this study provides a clear view of the $\mathrm{VaR}$ of individual indices. The $\mathrm{VaR}$ was estimated for each bond and sukuk index applying the historical VaR method. Here, it is observed that the VaR amount of sukuk indices is comparatively much lower than the VaR of bond indices in all the cases. Moreover, the inclusion of sukuk index with each bond index reduced the VaR around 30 to 50 per cent for all the developed, and emerging market bond indices are highlighted in Table II. The historical simulation shows that the inclusion of sukuk index improves the VaR significantly.

For analysis, hypothetical bond and sukuk portfolios were created with the same amount of dollar values (US\$1,000,000) offering different investment alternatives. Two types of the portfolio were constructed with the first one created combining sukuk and bond indices in the same portfolio, whereas the second one consisted of only bond indices. All six portfolios were constructed to measure the VaR separately. As explained in the methodology section, the variance-covariance matrixes were constructed to calculate the VaR. The confidence interval and the value of the holding period have to be specified in the VaR method. The selection of the holding period depends on the application. Though the industry uses daily VaRs for its internal risk control (Hartmann et al., 2004), the Basel Committee has advised banks to apply a holding period of 10 days as well as a 99 per cent confidence interval to maintain the minimum regulatory capital requirement to safeguard from market risk. A 99

\begin{tabular}{lll}
\hline No. & Indices & Ticker \\
\hline & Developed market & \\
1 & Bloomberg US Government Bond Index & BUSG \\
2 & Bloomberg Canada Sovereign Bond Index & BCAN \\
3 & Bloomberg Germany Sovereign Bond Index & BGER \\
4 & Bloomberg UK Sovereign Bond Index & BRIT \\
5 & Bloomberg Australia Sovereign Bond Index & BAUS \\
6 & Bloomberg Japan Sovereign Bond Index & BJPN \\
& & \\
1. & Emerging market & BSIN \\
2. & Bloomberg Singapore Sovereign Bond Index & BINDO \\
3. & Bloomberg Indonesia Local Sovereign Index & BMYR \\
4. & Bloomberg Malaysia Local Sovereign Index & BKRW \\
5. & Bloomberg S Korea Local Sovereign Index & BCGB \\
6. & Bloomberg China Local Sovereign Index & BINDI \\
7. & Bloomberg India Local Sovereign Index & DJSUKUK \\
8. & Dow Jones Sukuk Index & TRBPAMGOVI \\
\hline
\end{tabular}

Global sukuk and bond indices

1251

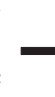




\begin{tabular}{|c|c|c|c|c|c|c|c|}
\hline $\begin{array}{l}\text { JIABR } \\
11,6\end{array}$ & No. & Bond index & $\begin{array}{l}\text { Individual VaR } \\
\text { for bond index }\end{array}$ & $\begin{array}{l}\text { VaR: bond index } \\
\text { with TRBPAMGOVI }\end{array}$ & $\begin{array}{c}\% \\
\text { change }\end{array}$ & $\begin{array}{l}\text { VaR: bond index } \\
\text { with DJSUKUK }\end{array}$ & $\begin{array}{c}\% \\
\text { change }\end{array}$ \\
\hline & 1 & BUSG & -14171.7 & -7593.51 & 46.61 & -9172.98 & 35.27 \\
\hline & 2 & BCAN & -13089.8 & -6945.17 & 46.94 & -7762.76 & 40.69 \\
\hline & 3 & BGER & -18209.8 & -9304.92 & 48.90 & -9869.53 & 45.80 \\
\hline & 4 & BRIT & -23727.1 & -11990.3 & 49.46 & -12986.6 & 45.26 \\
\hline & 5 & BAUS & -14609.3 & -7710.98 & 47.22 & -8574.47 & 41.30 \\
\hline & 6 & BJPN & -8141.66 & -4801.71 & 41.02 & -6013.08 & 26.14 \\
\hline & 7 & BSIN & -12589.8 & -7408.26 & 41.15 & -8283.92 & 34.20 \\
\hline & 8 & BINDO & -29966.6 & -16301.5 & 45.60 & -16611.4 & 44.57 \\
\hline & 9 & BMYR & -4360.91 & -4882.87 & -11.97 & -5074.81 & -16.37 \\
\hline & 10 & BCGB & -24357.4 & -12584.9 & 48.33 & -12940.6 & 46.87 \\
\hline & 11 & BINDI & -16662 & -8142.33 & 51.13 & -9317.28 & 44.08 \\
\hline & 12 & BKRW & -11195.6 & -6569.9 & 41.31 & -7418.41 & 33.73 \\
\hline VaR estimation (five & 13 & DJSUKUK & -7482.02 & -5248.983 & 29.84 & - & - \\
\hline days) & 14 & TRBPAMG & -5732.88 & - & - & -5248.983 & 8.44 \\
\hline
\end{tabular}

per cent confidence interval and five working days or a holding period of one week were selected in this study. Limited liquidity of positions is a strong reason for not selecting a daily holding period. The longer holding period was selected because of the relative illiquidity of sukuk, which is clear from the ratio of traded days.

The results of VaR calculation are presented in VaR estimates, and $\mathrm{VaR}$ was computed for a hypothetical portfolio worth of US $\$ 1,000,000$. Here, three portfolios have been created to calculate the VaR for developed market bond indices. The first portfolio consists of only six bond indices, the second portfolio consists of six developed market bond indices along with Malaysian sovereign sukuk index and the third portfolio is created by combining six developed market bond indices and global sukuk indices. Another three portfolios are constructed for the emerging market bonds following the same structure as the developed market, and altogether six portfolios are created to measure the VaR to determine whether sukuk plays a vital role in reducing the portfolio risk. These are presented in Table III.

The delta-normal method illustrates a VaR of US\$10206.51 for the portfolio of all developed market bond indices which means that the investor can be 99 per cent sure that the market value of the portfolio will not fall below US\$10206.51 within a week. In other words, the loss is capped at US\$10206.51 with a 1 per cent chance that it can lose more than that. In contrast, a portfolio of Malaysia sukuk and bond stands at US\$8582.21, which shows that the two figures differ from each other. Hence, with the inclusion of the Malaysian sukuk index in the portfolio, the probable loss is reduced to 15.91 per cent for the developed bond market investors based on the delta-normal method. Similar results were found by

No. of

portfolios Index selection $\quad$ Portfolio construction $(\$ 1 \mathrm{~m})$

Portfolio 1 Developed Market Bond indices

Portfolio 2 Emerging Market Bond indices

Portfolio 3 Developed Market Bond indices with Malaysia Sukuk Index

Portfolio 4 Developed Market Bond indices with Global Sukuk Index

Table III.

List of portfolios
Portfolio 5 Emerging Market Bond indices with Malaysia Sukuk Index

Portfolio 6 Developed Market Bond indices with Global Sukuk Index
Six indices weighted equally Six indices weighted equally

Seven indices weighted equally Seven indices weighted equally Seven indices weighted equally Seven indices weighted equally 
combining the global sukuk index with bond indices that reduced 15.84 per cent in VaR in the portfolio.

4.2.1 Value-at-risk estimates

Method Portfolio 1 Portfolio 2 Portfolio 3:

Global sukuk and bond indices

(1) Delta-Normal method:

- Developed Market 10206.51 8582.21 8589.32.

- Change 15.91 per cent 15.84 per cent.

(2) Historical Simulation:

- Developed Market 12035.5 10283.2 10283.7.

- Change 14.47 per cent 14.47 per cent.

Method Portfolio 4 Portfolio 5 Portfolio 6:

(1) Delta-Normal method:

- Emerging Market 6932.31 6056.43 5765.374.

- Change 10.56 per cent 12.63 per cent

(2) Historical Simulation:

- $\quad$ Emerging Market 8373.1 6056.43 7723.28.

- Change 6.14 per cent 7.76 per cent

The delta-normal method implies comparable results for emerging markets as well. By including the Malaysia sukuk index along with the emerging market bond indices in the same portfolio, VaR is reduced from $\$ 6932.31$ to $\$ 6056.43$, which is a 12.63 per cent reduction. Moreover, the VaR amount was reduced from $\$ 6932.31$ to $\$ 5765.37$ by combining the global sukuk with the emerging bond market indices in a portfolio, whereas in terms of percentage it is a 16.83 per cent reduction. It is observed that VaR of a portfolio which consists of sukuk and bond together is statistically different from the VaR of the portfolio, which consists of only bonds.

VaR estimates also presents the estimates of VaR using the historical simulation method. The results differ to the delta-normal method, whereas the numbers are very close, which indicate that the outcomes are robust to the method of calculation. The historical simulation method also illustrates that the inclusion of sukuk also improves the VaR in the portfolio. The decreases in the VaR amount stand at 14.47, 14.47, 6.14 and 7.76 per cent for the developed and emerging markets, respectively.

This study illustrates that sukuk can be considered diverse instruments that provide less risk of investment in a portfolio compared with bonds because of their different price behaviour. If a fixed-income investor wants to allocate his investment in bonds, it is advised that this investor incorporates sukuk in the investment portfolio, which can lead to gains in the diversification benefits as evidenced by this study. If an asset is not perfectly correlated with other assets in the portfolio, it is expected that some reduction in VaR might occur. Although, some reduction in $\mathrm{VaR}$ can be gained by adding another instrument to the portfolio in this study. However, the reduction in VaR in this study is because of not only the inclusion of an additional instrument in the portfolio but also an outcome of the different behaviour of sukuk prices in the secondary market in comparison with conventional bonds. In this context, Godlewski et al. (2013) found that the investors responded differently to the issuance of sukuk and bonds, whereas significant negative stock market responsiveness was found for sukuk issuance, the market is not responsive to bond issuance. The findings are similar to Raei and Cakir (2007) and Hassan (2012) who also found that inclusion of 
JIABR 11,6

sukuk in the portfolio reduces the VaR amount compared to a strategy of investing only in conventional bonds.

\section{Conclusion}

This study provides a clear view of the VaR of individual indices. It estimated the fiveday VaR for each bond and sukuk indices by applying the historical VaR method. Here, it was observed that the VaR amount of sukuk indices is comparatively much lower than the VaR of bond indices in all the cases. This can be because of the reasons that the Islamic investments are better positioned because of the specific features of Islamic investments such as, ethical and ratio screenings, exclusion of financial sectors, exclusion of highly leveraged firms, the limit of interest-based leverage and, finally, exclusion of using complex and intensive structured financial products, derivatives and other toxic assets (Saiti et al., 2014). Moreover, the inclusion of the sukuk index with each bond index reduced the $\mathrm{VaR}$ to around 30 to 50 per cent for all the developed and emerging market bond indices.

This study applied two different methods to estimate the VaR of the portfolios. A comparison of the two different approaches revealed that the inclusion of the Malaysian sukuk index in the portfolio contributed to a 15.91 per cent reduction in VaR for the developed market investors. The result is similar for the global sukuk index with a reduction of 15.84 per cent in VaR. Moreover, the delta-normal method implies comparable results for emerging markets as well. The results of the historical simulation are not similar to the delta-normal method, whereas the numbers are very close, which indicate that the outcomes are robust to the method of calculation. Hence, the results indicate that the VaR of a portfolio consisting of sukuk and bonds is not similar to a portfolio which represents only bonds.

Although there is some reduction in VaR which can be gained by adding another instrument, this reduction is not because of adding an instrument in the portfolio; rather it is an outcome of the different behaviour of sukuk prices in the secondary market compared with conventional bonds. In relation to this, Godlewski et al. (2013) found that the investors responded differently to the issuance of sukuk and bonds. Hence, sukuk can be considered a different type of instrument compared with bonds because of their different price behaviour. Finally, the VaR concept is a very useful tool for financial institutions with regards to their risk management, and international fixed-income investors are advised to incorporate sukuk in the investment portfolio along with bonds which may help to gain diversification benefits as shown from this study.

\subsection{Policy implications of the study}

Diversification benefits cannot be supported theoretically without investigating the extent of financial interdependence. In this context, this study uncovered the attractive opportunities in terms of diversification benefits with credit quality and Shariah-compliant financial sector exposure for investors who want to invest in fixed-income securities. An effective diversification strategy will provide possible scope for markets to retain financial stability and boost system efficiency, which is essential for policymakers, portfolio managers and investors.

\subsection{Limitations of the study}

This research examined the financial market integration only at the bond index level. Comprehensive studies can be conducted to analyse the market on a sectoral basis. This study focused solely on the sovereign bond and sukuk markets while it is still essential to 
investigate the corporate sukuk market. Another shortcoming of this study includes the lack of data from a longer timeframe. This research covered only six years of data; however, a detailed study using data from a longer period is needed because it will provide an in-depth analysis of sukuk markets. It will also be a practical step for future research in financial economics and international finance.

\section{Notes}

1. World Bank, US Census Bureau (2013 estimate).

2. Data sourced from Bloomberg.

3. Federal Open Market Committee (FOMC) cut interest rate to 0.25 effective 16 December 2008 (Bloomberg).

\section{References}

Afshar, T.A. (2013), "Compare and contrast sukuk (Islamic bonds) with conventional bonds, are they compatible?", Journal of Global Business Management, Vol. 9 No. 1, p. 44.

Ahmad, N., Daud, S.N.M. and Kefeli, Z. (2012), "Economic forces and the sukuk market", Procedia Social and Behavioral Sciences, Vol. 65, pp. 127-133.

Alexander, C. (2009), Market Risk Analysis, Value at Risk Models, Vol. 4, John Wiley and Sons, West Sussex.

Alswaidan, M.W., Daynes, A. and Pasgas, P. (2017), "Understanding and evaluation of risk in sukuk structures", Journal of Islamic Accounting and Business Research, Vol. 8 No. 4, pp. 389-405.

Ariff, M. and Safari, M. (2012), “Are sukuk securities the same as conventional bonds?”, Afro Eurasian Studies, Vol. 1 No. 1, pp. 101-125.

Ben Jedidia Khoutem, D. (2014), "Islamic banks-sukuk markets relationships and economic development: the case of the Tunisian post-revolution economy", Journal of Islamic Accounting and Business Research, Vol. 5 No. 1, pp. 47-60.

Bhuiyan, R.A., Rahman, M.P., Saiti, B. and Ghani, G.M. (2018), "Financial integration between sukuk and bond indices of emerging markets: insights from wavelet coherence and multivariateGARCH analysis", Borsa Istanbul Review, Vol. 18 No. 3, pp. 218-230.

Bhuiyan, R.A., Rahman, M.P., Saiti, B. and Ghani, G.M. (2019a), "Co-movement dynamics between global sukuk and bond markets: new insights from a wavelet analysis", International Journal of Emerging Markets, Vol. 14 No. 4, doi: 10.1108/IJOEM-12-2017-0521.

Bhuiyan, R.A., Rahman, M.P., Saiti, B. and Ghani, G.B.M. (2019b), "Does the Malaysian sovereign sukuk market offer portfolio diversification opportunities for global fixed-income investors? Evidence from wavelet coherence and multivariate-GARCH analyses", The North American Journal of Economics and Finance, Vol. 47, pp. 675-687.

Fathurahman, H. and Fitriati, R. (2013), "Comparative analysis of return on sukuk and conventional bonds", American Journal of Economics, Vol. 3 No. 3, pp. 159-163.

Godlewski, C.J., Turk-Ariss, R. and Weill, L. (2013), "Sukuk vs conventional bonds: a stock market perspective”, Journal of Comparative Economics, Vol. 41 No. 3, pp. 745-761.

Hamzah, S.R., Ismath Bacha, O., Mirakhor, A. and Abdul Kader Malim, N. (2018), "Empirical evidence of risk shifting in bonds and debt-based sukuk: the case of Malaysian corporations", Journal of Islamic Accounting and Business Research, Vol. 9 No. 5, pp. 687-700.

Hartmann, P., Straetmans, S. and Vries, C.D. (2004), "Asset market linkages in crisis periods", Review of Economics and Statistics, Vol. 86 No. 1, pp. 313-326.

Hassan, K.A. (2012), “Comparison between sukuk and conventional bonds: value at risk approach", Master's thesis, West minter University, doi: 10.2139/ssrn2215194. 
JIABR 11,6

Jorion, P. (2006), Value at Risk, McGraw-Hill, New York, NY.

Kuwait Finance House Research Ltd. (2015), “Global sukuk market-2015 outlook”, Kuwait Finance House Research.

Lahsasna, A. and Lin, L. (2012), "Issues in islamic capital markets: Islamic bond/sukuk", Proceedings from the 3rd International Conference on Business and Economic Research 12-13 March 2012, Bandung.

Malaysia International Islamic Financial Centre (2014), “Global sukuk report 2014”, Malaysia International Islamic Financial Centre, Kuala Lumpur.

Nasir, A. and Farooq, U. (2017), "Analysis of value at risk of sukuk and conventional bonds in Pakistan”, Journal of Islamic Accounting and Business Research, Vol. 8 No. 4, pp. 375-388.

Paltrinieri, A., Dreassi, A., Miani, S. and Sclip, A. (2015), "In search of zero beta assets: evidence from the sukuk market", International Journal of Social, Behavioral, Educational, Economic and Management Engineering, Vol. 9 No. 1, pp. 67-75.

Raei, F. and Cakir, S. (2007), "Sukuk vs. eurobonds: is there a difference in value-at-risk? (No. 7-237)", International Monetary Fund, Washington, DC.

Rahman, M.P., Omar, M.A. and Kassim, S.H. (2013), "An application of GARCH modeling on the Malaysian sukuk spreads”, Journal of Islamic Finance, Vol. 2 No. 2.

RAM Rating Services Berhad (2008), Malaysian Sukuk Market Handbook. Your Guide to the Malaysian Islamic Capital Market, Tijanimas Communications Sdn Bhd, Kuala Lumpur.

Ramasamy, R., Munisamy, S. and Helmi, M.H.M. (2011), "Relative risk of Islamic sukuk over government and conventional bonds", Global Journal of Management and Business Research, Vol. 11 No. 6.

Razak, S.S., Saiti, B. and Dinç, Y. (2018), "The contracts, structures and pricing mechanisms of sukuk: a critical assessment", Borsa Istanbul Review, doi: 10.1016/j.bir.2018.10.001.

Saiti, B., Bacha, O.I. and Masih, M. (2014), "The diversification benefits from Islamic investment during the financial turmoil: the case for the US-based equity investors", Borsa Istanbul Review, Vol. 14 No. 4, pp. 196-211.

Sherif, M. and Erkol, C.T. (2017), "Sukuk and conventional bonds: shareholder wealth perspective", Journal of Islamic Accounting and Business Research, Vol. 8 No. 4, pp. 347-374.

Smolo, E. and Mirakhor, A. (2010), "The global financial crisis and its implications for the Islamic financial industry", International Journal of Islamic and Middle Eastern Finance and Management, Vol. 3 No. 4, pp. 372-385.

Tariq, A.A. (2004), Managing Financial Risks of Sukuk Structures, Loughborough University, UK.

Wilson, R. (2010), "Islamic capital markets: the role of sukuk", Islamic Finance Instruments and Markets, pp. 57-60.

Zin, M., Sakat, A., Ahmad, N., Nor, M., Bhari, A., Ishak, S. and Jamain, M.S. (2011), “The effectiveness of sukuk in Islamic finance market", Australian Journal of Basic and Applied Sciences, Vol. 5 No. 12 , pp. $472-478$.

\section{Further reading}

Philippe, J. (2006), Value at Risk, McGrew-Hill, New York, NY.

Corresponding author

Buerhan Saiti can be contacted at: borhanseti@gmail.com

For instructions on how to order reprints of this article, please visit our website:

www.emeraldgrouppublishing.com/licensing/reprints.htm

Or contact us for further details: permissions@emeraldinsight.com 